\title{
LA EXPERIENCIA MÍSTICA EN SUMA DE CLARIDADES DE LAUREANO ALBÁN
}

\author{
RONALD CAMPOS LÓPEZ \\ Universidad de Costa Rica \\ Universidad de Valladolid \\ ronaldcl84@yahoo.com
}

\section{RESUMEN}

En el poemario Suma de claridades (1992), del costarricense Laureano Albán, la experiencia mística se desarrolla en torno a la mirada, el recuerdo, la visión onírica de la infancia, los paisajes de la niñez, la claridad, las figuras del niño, el padre, la madre y la hermana. Para el análisis hermenéutico, se define el concepto de misticismo. Se interpretan algunos símbolos según las estructuras antropológicas del imaginario de Gilbert Durand. Se establece el cronotopo de la experiencia mística del sujeto lírico. Se observa el paso desde la noche angustiante hasta el ambiente diurno y onírico donde trascienden las experiencias inconscientes y religiosas que llevan al sujeto lírico hasta una vivencia cósmica y sagrada. Igualmente, se observa la materialización de los arquetipos junguianos del niño, el padre, la madre y el anima, los cuales configuran una cuaternidad en la realidad imaginaria, ontológica, existencial y mística del sujeto lírico.

PALABRAS ClaVE: Poesía costarricense, Laureano Albán, mística, imaginación simbólica, infancia, arquetipos

THE MISTICAL EXPERIENCE IN SUMMA OF CLARITIES OF LAUREANO ALBÁN

ABSTRACT

The mystical experience develops around the look, the memory, the dreamlike vision of childhood, childhood landscapes, the clarity, and the figures of the child, father, mother and sister, in Summa of Clarities (1992), of the Costa Rican poet Laureano Alban. For the hermeneutical analysis, the concept of mysticism is defined. The symbols are interpreted according to the anthropological structures of the imaginary of Gilbert Durand. The chronotope of the lyrical subject's mystical experience is established. The passing from distressing night to diurnal and dreamlike environment is observed. In this environment, the unconscious and religious experiences cut across and they bring the lyrical subject to a cosmic and holy life. The realization of the Jungian archetypes of the child, father, mother and anima is equally observed. These archetypes configure a quaternity in the imaginary, ontological, existential and mystical reality of lyrical subject.

KEYWORDS: Costa Rican poetry, Laureano Alban, mysticism, symbolic imagination, childhood, archetypes

\section{ACERCA DEL POETA Y EL POEMARIO}

Laureano Albán nació en Santa Cruz de Turrialba (Costa Rica), el 9 de enero de 1942. Desde joven se distinguió en su localidad por su dedicación a las letras junto a Jorge Debravo (1938-1967) y Marco Aguilar (1944- ), quienes crearon en 1957 el Grupo de Poetas de Turrialba. Albán viajó luego a San José, donde creó 
con Debravo, el 14 de octubre de 1961, el Círculo de Poetas Costarricenses (aún vigente). En 1974, firmó el Manifiesto trascendentalista, junto a Julieta Dobles, Ronald Bonilla y Carlos Francisco Monge. Este fue el primer manifiesto literario redactado en Costa Rica, y del cual deriva el primer movimiento literario producido y promovido como tal en este país y además exportado a España y difundido a través del Grupo Trascendentalista de Aranjuez, dirigido por la poeta Montserrat Doucet.

Albán cursó estudios de filología y lingüística en la Universidad de Costa Rica y realizó sus estudios doctorales en literatura hispanoamericana en la Universidad Estatal de Nueva York, en Stony Brook. Ha dictado cursos, conferencias y talleres sobre creación literaria en universidades e instituciones académicas. Fungió como presidente de asociaciones de escritores y editoriales costarricenses. Fue ministro consejero de la Embajada de Costa Rica en Madrid (1981-1983); en Nueva York, delegado cultural de Costa Rica ante la ONU y embajador cultural ante los Estados Unidos (1983-1986); embajador plenipotenciario de Costa Rica en Israel (1987-1990); y embajador de Costa Rica ante la Unesco, en París (1998-2002). En 2004, ingresó como miembro de número a la Academia Costarricense de la Lengua, donde ocupa la silla D. En 2006, mereció el máximo reconocimiento cultural y literario otorgado en Costa Rica: el Premio Magón. Desde 1996 se encuentra nominado al Premio Nobel de Literatura.

Hasta la actualidad, Albán es, como reconocieron Charpentier (1994) y Bulgarelli (1995), el poeta costarricense con más premios y triunfos obtenidos en el extranjero. Entre sus galardones se encuentran el Premio Adonáis (Madrid, 1979), Nacional de Poesía (Costa Rica, 1980, 1993), Hispanoamericano de Literatura Juan Ramón Jiménez (Huelva, 1981), Cultura Hispánica (Madrid, 1981), Anual de Columbia University Translation Center (New York, 1983), Internacional de Poesía Religiosa (Burgos, 1983), Bienal de Poesía (León, España, 1985).

La producción poética albaniana ha sido publicada en Costa Rica, Portugal, España, Italia, Jerusalén, Alemania, Francia y Estados Unidos; y traducida al inglés, italiano, francés, alemán y hebreo. Varios poemas suyos se incluyen en antologías americanas y europeas. Su producción poética es, en fin, una de las más significativas en la historia literaria de la segunda mitad del siglo XX y principios del XXI de América Latina. Presenta, desde una perspectiva trascendentalista, una variedad estilística $\mathrm{y}$ temática: lo sociopolítico, lo existencial, la herencia mítica y ancestral de las culturas indoamericanas, el erotismo; la cotidianidad de instrumentos, seres humanos, mitológicos, conceptos; el misticismo, entre otros.

Dentro de su producción mística, se encuentra Suma de claridades, el cual obtuvo en 1986 el Premio de Poesía Walt Whitman, de la Fulbright Foundation (Estados Unidos); y en 1989, el Premio Mundial Fernando Rielo de Poesía Mística (Madrid). Por eso, su edición de 1992 es bilingüe (español-inglés). 
Suma de claridades ha sido casi inexplorado por la crítica. Los poemas «Nocturno mínimo»y «La mirada incesante» fueron publicados, el 5 de septiembre de 1993, por el periódico costarricense La Nación, con motivo del Premio Fernando Rielo. Fornoff y McClintock (1995) son los únicos quienes lo mencionan cuando aún Albán se refería a él con un primer título: Geografía del delirio. Ospina (2003) observa que la claridad intuitiva del poeta le viene desde la infancia. Doucet (2010) se refiere a este poemario como poesía mística. Según Pieragnolo, en este texto se «recupera la intensa influencia y la emoción de los lugares de su infancia y su familia originaria» (2011: 9, traducción mía). Campos (2015) ubica este poemario dentro de la etapa de madurez de la producción poética de Albán.

Frente a estos comentarios generales ofrecidos por la crítica, ¿cómo se desarrolla realmente el misticismo en este poemario?

\section{APROXIMACIÓN AL CONCEPTO DE MISTICISMO}

Para comprender el fenómeno místico en su amplitud, se debe librar stricto sensu al término «experiencia religiosa»o «experiencia mística» de indicar cualquier conjunto de dogmas, doctrinas o racionalismos propios de cualquier institución (Otto 1925); es decir, no debe encontrarse subordinado a ninguna finalidad o moralidad. Entiéndase «religión» en el exacto valor etimológico de religare: \{re-\}: repetición y \{ligare\}: ligar, amarrar; o sea, la empresa mística del ser por ligarse de nuevo con lo numinoso y cósmico, con el ganz andere, con lo sagrado por excelencia en sus dos aspectos misteriosos (lo tremendo y lo fascinante). «Religión» corresponde, pues, al «vivo sentimiento de lo numinoso» (Otto 1925: 142), al comienzo de la verdadera vita religiosa.

La palabra «mística» procede del adjetivo griego antiguo mystikòs, derivado de myein: «cerrar los ojos», «cerrar la boca»; de ella proceden «miope», «mudo»y «misterio». Por eso, «remite a algo oculto, no accesible a la vista, de lo que no puede hablarse» (Velasco 2004: 16). De ahí que Bertín afirme:

El misticismo es esencialmente la tentativa de sacar el yo de los límites de la naturaleza humana, transportándolo a un nuevo plano en el que toda oposición entre el yo y el mundo, el hombre y la realidad, toda oposición espacial y temporal, ceden ante un sentimiento de la divinidad que trasciende inteligencia, voluntad y sentimiento individual (1967: 39).

Así pues, toda experiencia mística corresponde a un episodio más o menos breve en que un sujeto, desde su vida cotidiana, establece una relación con una realidad -dimensiones o aspectos de lo real- que lo supera (Roy 2001). Agrega Velasco: 
En el contexto religioso tales experiencias son una modalidad concreta de realización de la respuesta humana que origina el conjunto de la vida religiosa: la del reconocimiento, la aceptación, la acogida de la presencia de esa realidad enteramente trascendente que se le desvela y se le autoentrega desde lo más íntimo de su propia intimidad (2004: 26).

La unio mystica es la raíz, el contenido y la meta de estas experiencias que originan y convocan una realidad enteramente anterior y superior al ser y el funcionamiento ordinario de sus sentidos y facultades. En consecuencia, el homo religiosus no se comporta como sujeto de una realidad objetiva: él es tomado, poseído por la experiencia fruitiva que lo invita a unificarse con lo numinoso (Velasco 2004).

Las categorías para expresar dicha esencia varían: éxtasis, contemplación, visión de Dios, deificación, estado teopático, entre otras. La realización de este ideal depende de la comprensión que se le dé a la figura divina según el contexto vital y religioso (Velasco 2004). Aun así, McGinn $(1989,1992)$ propone dos formas principales de unión mística.

En primer lugar, la unitas indistinctionis implica una contemplación intelectual de lo divino y una unificación ontológica y sustancial entre el ser religioso y la realidad contenido de su experiencia, de acuerdo con las llamadas místicas de la esencia, especulativas o de la unidad en lo Absoluto. Según esta clase de místicas, el conocimiento es fundamentalmente introversivo, o sea, la énstasis: la introversión, fusión y transformación del ser en lo más profundo de sí; como diría García Gual: ver «hacia dentro con renuncia a los sentidos, especialmente al de los ojos dirigidos al mundo externo, en sus secretos procesos hacia lo interno» (2011: 164).

En segundo lugar, la unitas spiritus es la unión afectiva, operacional, realizada por voluntad y amor, según las místicas teístas, esponsales o del encuentro. Según este tipo de místicas, puede denominarse extroversiva, pues su proceso culmina con el éxtasis, esa relación que Paz (1971) entiende como la revelación poética y consagración del instante, pues siempre «trae consigo otras significaciones como euforia, alegría y admiración» (Sancho 2009: 14) y, en consecuencia, el sujeto intenta reunirse con la alteridad (su objeto), ya sea su consciencia interior-profunda, ya la amada, ya la divinidad, ya la naturaleza, entre otros, a través de ritmos e imágenes creativas (Paz 1971, 1998).

Velasco (2004) reflexiona posteriormente sobre las formas expuestas por McGinn y propone una tercera. Las místicas de la nada, el vaciamiento o la ausencia presentan la unión o paso hacia la nada; verbigracia: el nirvana budista, un camino de liberación del sufrimiento, de eliminación del sujeto empírico o natural -mas no su aniquilación-, de vaciamiento como vía de salvación.

En ocasiones, las tres formas de unión mística aparecen diferenciadas según el papel del «intelecto y el amor en el camino hacia la unión y en el disfrute de la misma» (McGinn 1992: 85), o de la viabilidad hacia la nada 
(Velasco 2004). Otras veces, aparecen imbricadas, relativizadas, «dado el carácter paradójico del lenguaje de los místicos, la naturaleza verdaderamente dialéctica de sus experiencias y la condición de 'más allá de la coincidentia oppositorum', de la realidad-contenido de las mismas» (Velasco 2004: 39).

De todas maneras, los conocimientos procurados por la unión mística son cualitativamente distintos de los alcanzados mediante los sentidos en la realidad objetiva y fenomenológica. Tal saber constituye una inmediatez mediada:

«inmediato» en la medida en que nada ajeno al sujeto en su centro más personal se interpone entre la presencia divina y su propio ser. Pero tal inmediatez se declara mediana porque es en la huella de la acción de Dios en el alma, en el alma misma convertida toda ella en medio de percibir a Dios [...], donde se le refleja al hombre la Presencia (Velasco 2004: 33).

Se llama estado de unión al término del proceso místico, cuando: «el sujeto llega a 'realizar' personalmente, asumiéndola consciente y amorosamente, la presencia del Misterio en el centro de su ser personal que ha hecho posible y ha desencadenado todo el proceso» (Velasco 2004: 34). Este estado ha de introducir cambios en la forma de conocer: genera una transconsciencia, por la cual se puede padecer una especie de suspensión de todas las facultades y funcionamientos ordinarios. Esta suspensión, no obstante, «no condena al sujeto a la inconsciencia, dado que hasta en el éxtasis entra el sujeto con plena conciencia y lo vive con alguna forma de conciencia que le permite después recordar lo vivido y describirlo con notable precisión» (Velasco 2004: 34). Quienes llegan a la transconsciencia «comienzan a ver todo en Dios y desde Dios»; es decir, experimentan una actitud deísta: una noción filosófica de la divinidad, donde el Ser es visto como lo absoluto, fundamento de las existencias, causa y finalidad primeras; el numen es el Ente supremo. Él es lo trascendente. Así, la contemplación se vuelve consecuencia de la unión y la fecundidad espirituales del homo religiosus.

En resumen, la experiencia mística es la presencia inobjetiva del misterio divino en el ser (Velasco 2004). Es la culminación de la experiencia intuitiva y religiosa en su originalidad plena (García-Baró 2004). Lo místico es itinerario hacia la plenitud de la evolución humana y, por ello, afecta al centro del hombre y se manifiesta desde ese mismo centro en todas sus actividades. La experiencia mística es universal y su universalidad es constitutiva (Schimmel 1996). En todo lo místico, se dan fenómenos, porque lo místico es dialogal, manifestativo y envolvente; $\mathrm{y}$, por tanto, puede ser observable y objeto de estudio (Pascual 2004).

\section{CLARIDAD DE CLARIDADES: UN ANÁLISIS HERMENÉUTICO}


Desde el comienzo, simplemente por el hecho de haber nacido, de vivir, el sujeto lírico de Suma de claridades se enfrenta al tiempo, el mundo y la noche profanos, convencido de que estos existen pero no son lo real; por eso, utiliza la negación:

Oíd el mundo.

No es una larga larga ceniza iluminada.

No es el sombrío secreto del pasado abismándose.

$\mathrm{Ni}$ el pavor de la estatua de sal de la memoria

deshaciéndose al fondo de lo nunca nacido.

$[\ldots]$

Ahí se aprende a nacer.

Y naciendo se asume

la alta, inconmutable

soledad de estar vivo. (Albán 1992: 46 y 70)

El devenir temporal, el mundo y la noche profanos se encuentran representados por símbolos nictomorfos («sombrío secreto») y catamorfos («ceniza», «abismo», «pavor», «fondo», «soledad»). Recuérdese que los nictomorfos son aquellos símbolos asociados al ámbito de las tinieblas y la oscuridad; mientras los catamorfos remiten a la caída, el abismo y la carne (Durand 1982). De los símbolos catamorfos anteriores, el primero, tercero y quinto constituyen innovadores en la producción poética albaniana (Campos 2016) y, con frecuencia, redundan no solo en este poemario sino también, por ejemplo, en Geografía invisible de América (1982), Érase una vez al-Ándalus (1991) e Infinita memoria de América (1991). En fin, con los símbolos nictomorfos y catamorfos susodichos se representa imaginariamente la angustia frente a la realidad. Sin embargo, «cada cosa puede reducirse a su sombra/ y por ello se aprende a mirarla en su muerte» (Albán 1992: 80). La mirada se convierte en el instrumento contemplativo y revelador con que el sujeto lírico eufemiza la noche angustiante en una noche mística. La mirada sobre el mundo fenomenológico equivale a la mirada del recuerdo sobre el mundo interior:

Que mirar es el único ejercicio del cielo y una sabiduría que se aprende despacio.

La mirada es un don que crea lejanías y en ellas reconoce espejismo o destinos.

No se nace mirando, se nace deslumbrado. Y por ello se vive subiendo hacia ventanas de luz interminable.

$[\ldots]$ 


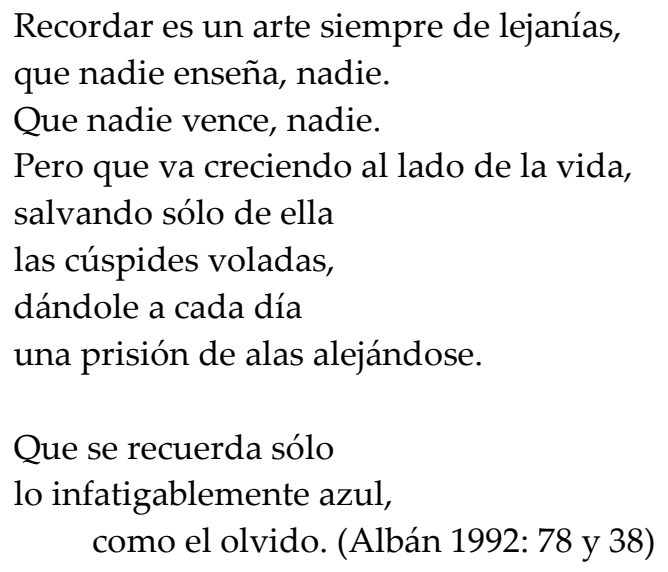

Para el sujeto lírico las acciones de mirar y recordar son una misma, puesto que ambas generan el asombro del misterio fascinante y proporcionan el conocimiento intuitivo y trascendental, representado por símbolos ascensionales: «lejanías», «cúspides», «alas», «cielo». Durand (1982) relaciona los símbolos ascensionales con la posición erguida, la sublimidad, la verticalidad espiritual, la ascensión, la soberanía (militar, jurídica, religiosa).

Según Chevalier y Gheerbrant: «La luna es símbolo de conocimiento indirecto, discursivo, progresivo, frío» (1988: 658). Gracias a la mirada y el recuerdo, la luz nocturna y lunar, que orienta la percepción racional y existencia profana, poco a poco es sustituida por una claridad estelar mística:

\author{
la muerte que anuncia potestades \\ sombrías como dardos, en su lunar manera \\ de aparecer, ya olvido, en mí. \\ $[\ldots]$ \\ el arte de dar \\ transparencia a la noche \\ hasta que quede sólo \\ la estrella en lo mirado. (Albán 1992: 114 y 36)
}

La luz de la «estrella» aparece como un símbolo espectacular. Estos últimos se asocian con la luz, lo solar, la videncia y la palabra (Durand 1982). Por eso, la luz estelar vence la oscuridad ya que, al ser un centro luminoso del universo, representa las fuerzas espirituales, una vía hacia el conocimiento celestial, los deseos del ser por situarse con los ritmos cósmicos y armonizarse con ellos (Chevalier y Gheerbrant 1988). Debido a la mirada y el recuerdo, pues, la intensidad de la experiencia mística aumenta, hasta el punto de que la luz estelar se convierte en luz solar:

Porque el día es un reino

del que sólo miramos

su brevedad en llamas. 
Pero el día no cesa,

y viene galopando desde el primer milagro

donde no estaba el hombre. (Albán 1992: 84)

Con estos cambios de intensidad lumínica, el espacio nocturno negativo y el tiempo histórico son eufemizados $\mathrm{y}$, por tanto, sustituidos por un ámbito pleno y espectacular, y un tiempo cíclico y onírico:

En las manos deslumbra

sólo la luz que basta.

No se posee más mundo

que lo siempre cantado.

El tiempo es una casa

invadida del todo

por alucinaciones,

como rosas deseadas. (Albán 1992: 42)

Ya lo sugiere esta última estrofa: tiempo y espacio se (con)funden en una experiencia mística, ya que toda vivencia religiosa se enmarca en un cronotopo específico. En este caso, para el sujeto lírico el «prado»-símbolo ascensional redundante en la poesía albaniana (Campos 2016)- es el centro donde convergen la mirada, el recuerdo; donde (co)existen de nuevo, en el instante poético-místico, la infancia, los asombros, el gozo, la claridad, el conocimiento y lo trascendente:

Voy por un prado, y cada paso

tiene y crea latitudes de lluvia.

Si yo corro por él,

él existe y me llama

a existir en lo diáfano.

Porque es un prado el día

más claro de la infancia,

que nunca se termina de recorrer.

En él todas las cosas

perfectamente vivas como lámparas,

se iluminan a solas, detenidas

en los ojos que vuelan.

Si yo camino sé que las cosas más vivas

conmigo caminando se hacen interminables,

se tornan transparentes

como lo que no cesa. (Albán 1992: 96)

Abril es el mes más cálido en Costa Rica. Quizá esta referencia lleva a que el sujeto lírico evoque este mes como el momento de mayores claridades 
cenitales y cercanía al más intenso calor uránico: «Sonoro el mes de abril/ duele de transparente» (Albán 1992: 28). Se observa, pues, un isomorfismo de símbolos espectaculares («luz», «azul», «día», «transparencia», «abril»), que iluminan la existencia y estimulan la experiencia mística.

Este estímulo es tal, que para el sujeto lírico: «La primera mirada tiene forma de bosque/ o de mínima lámpara hundida entre mañanas» (Albán 1992: 78). Esta mirada contemplativa le genera recordar, o más bien intuir, su procedencia primigenia, ya que la tierra es la matriz de donde viene y adonde regresa el ser física, psíquica y espiritualmente:

Puede olvidar el hombre el futuro o la dice
puede quemar el tiempo las páginas o el
puede oxidar la noche los días del diam
pero nunca a la tierra
y su fatal memoria de galopes lejanos.
[...]
Que el espacio terrestre
siempre será el primero,
inagotable día convocado.
[...]
Que sólo vive el hombre
por amor a la tierra,
y la tierra lo sabe. (Albán 1992: 28 y 32)

Gracias a la fantasía uterina universal de la creación, el simbolismo de la tierra en estos versos materializa el arquetipo de la tellus mater, pues esta sustancia primordial es capaz de dar la vida y al mismo tiempo quitarla (Chevalier y Gheerbrant 1988). Por eso, el sujeto lírico expresa su deseo de reintegrarse con la «tierra» y dejar de ser uno distinto de la plenitud cósmica. De ahí que enumere una lista de elementos y fenómenos naturales, que van desde lo macrocósmico («noche» o «amanecer») hasta lo microcósmico («azufre»), con el propósito de expresar su intenso deseo de ser parte la naturaleza («lluvia», «viento», «pájaros», «rocío», «bosques»), armonizarse con ella, reintegrarse con el Uno: la fuente, el contenido y el fin de toda experiencia mística, cuyo carácter tremendo, mayestático, misterioso y augusto motiva el acaecer cósmico (Otto 1925), pues Ello es el cosmos mismo; el Uno sorprendente, sublime, superior en realidad y poder:

\footnotetext{
Yo no quiero ser niño, quiero ser sólo lluvia. Yo no quiero volver a las blancas memorias. Quiero ser sólo viento, y la cruz de dos pájaros
} 
mínimos que se aman, se hieren y se pierden en la pasión del viento.

Quiero la alta moneda brillante del rocío.

Quiero ser una noche de lejanías y bosques $\mathrm{y}$ amanecer vencido por los ríos y el aire. O cruzar empapado la neblina más última. O tocar el azufre y su inútil diamante. O escuchar el ganado bramando en la tormenta como un pavor ausente.

Yo no quiero ser niño, quiero ser sólo niebla, tan infinitamente húmedo como ella, tan transparentemente azul como su sombra. (Albán 1992: 40-42).

En estas estrofas, llaman la atención tres deseos relacionados con tres símbolos particulares.

En primer lugar, la «niebla» se homologa a la claridad, la «transparencia», la «luz» y lo «azul», en tanto sugiere lo informe de lo sagrado. Ella representa lo indeterminado, el caos de los orígenes, la confusión en el tránsito del tiempo; ella precede las revelaciones, es preludio de la manifestación divina (Chevalier y Gheerbrant 1988). Por eso, el sujeto lírico desea «cruzar empapado/ la neblina más última». Obsérvese cómo, estilísticamente, en este caso y en los dos siguientes, se emplea la optación por deseo vehemente. El sujeto lírico desea adentrarse en la «niebla», traspasar su «humedad» y empaparse de ella, porque esta es la frescura y la potencia de lo sagrado representado por el agua que procede ya del cielo («rocío»), ya de la tierra por evaporación. Así pues, para el sujeto lírico, la «niebla» aparece más como un símbolo de la inversión, antes que nictomorfo, dado que connota la indistinción del ser respecto del infinito pleroma divino, manifiesto materialmente en el cosmos. Considérese que los símbolos de la inversión pertenecen al régimen nocturno y buscan eufemizar todos los valores del régimen diurno a través del esquema del descenso (Durand 1982). Contemplando la «niebla» y sintiendo su «humedad», pues, el sujeto lírico llega a intuir que:

No hay un deseo mayor que el de la transparencia.

Las cosas y los seres 
son poseídos siempre

por un final de niebla. (Albán 1992: 84)

En segundo lugar, el sujeto lírico desea «tocar el azufre/ y su inútil diamante». En este par de versos se entrecruzan dos discursos que enriquecen la expresión del sujeto lírico albaniano. Por un lado, resuena el discurso bíblico (Job 18: 15), en el que el «azufre» aparece como un símbolo de esterilidad; por otro, el discurso alquímico, según el cual, por su color, el «azufre» se asocia con el fuego y lo solar y, por tanto, representa el principio activo, manifiesta la voluntad divina y la actividad espiritual (Chevalier y Gheerbrant 1988). Estas dos connotaciones se imbrican en el deseo del sujeto lírico, de modo que su aparente acto de tocar el azufre «inútil» en realidad constituye su anhelo de sufrir la quemadura, sentir el calor, de este no metal y, por consiguiente, afectar su naturaleza profana y provocar una transformación en su naturaleza sagrada. $\mathrm{El}$ «azufre», en estos versos, por tanto, aparece como un símbolo espectacular.

En tercer lugar, el sujeto lírico desea «escuchar el ganado/ bramando en la tormenta/ como un pavor ausente». El paso trágico del tiempo está representado por el símbolo teriomorfo («tormenta») y la reiteración "pavor» catamorfo. Por su parte, los símbolos teriomorfos refieren a la monstruosidad animal, las inclemencias y catástrofes meteorológicas, el movimiento fugaz, cambiante, doloroso y caótico del tiempo (Durand 1982). Así pues, ante los símbolos teriomorfo y catamorfo anteriores, se anhela el bramido de los bovinos, los cuales se relacionan con la fecundidad agraria y los períodos cíclicos y regeneradores lunares, debido a la asociación de los cuernos de estos animales con los cuernos de la luna creciente (Eliade 1974, Durand 1982). El bramido del «ganado», por tanto, consuela al sujeto lírico y lo lleva a replegarse ante el tiempo histórico y encontrar asilo en el tiempo cíclico del cosmos.

La «niebla», el «azufre» y el «ganado», en fin, constituyen un isomorfismo de símbolos de la inversión, espectacular y cíclico como respuesta al devenir temporal y la realidad profanos. Este particular isomorfismo refuerza la idea del sujeto lírico de transformarse física y espiritualmente, emprender su unio mystica, hasta reintegrarse absolutamente con el Uno.

Como se observa hasta el momento, el sujeto lírico se visualiza en su experiencia mística como un niño que corre sobre la plenitud del «prado», del cosmos, en «abril»:

Toco la tierra, madre de mi sombra.

Por ella corre un niño

infatigablemente imaginado.

$[\ldots]$

Por ella corre un niño

remotamente siempre

llamando las distancias. 
Yo me acerco y lo nombro.

Yo me acerco y lo abrazo.

Pero él corre por prados de lunas espejeantes,

por bosques donde el cielo es un árbol azul,

por nieblas donde el tiempo es una fruta pálida.

Entra y sale del día

con la inocencia rápida

de la flor en la lluvia.

Alguien lo está llamando

desde lejanas lámparas.

Y él corre sin saber

que no sale de la única

tierra de la memoria. (Albán 1992: 28-32)

Él va corriendo, siendo uno con la «tierra», la «lluvia», el «bosque», la «niebla» y la «memoria», hacia el encuentro con lo real, lo trascendente, «hacia las hondas casas/ de la luz invisible» (Albán 1992: 32), porque justamente «Alguien lo está llamando» desde sus profundidades inconscientes, simbólicas, intuitivas, místicas. Ese «Alguien»-obsérvese el valor retórico del pronombre indefinido- es, sin dudas, el incognoscible Ser numinoso que, desde lo profundo de la psique, la «tierra» y el cosmos, convoca al ser humano, por su doble naturaleza y pertenencia (profana y sagrada), para que se reúnan místicamente. De ahí que el sujeto lírico intuya que:

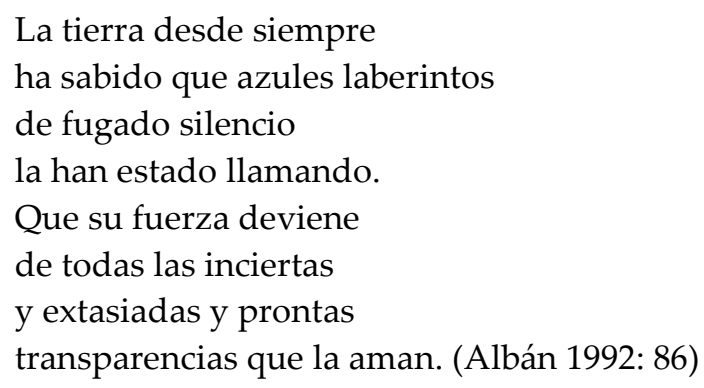

Gracias a su «primera mirada» de niño, el sujeto lírico intuye y vive en el microcosmos la trascendencia y el misterio del macrocosmos, lo sagrado, el Uno. La recurrencia al motivo de la «tierra» primordial y los espacios cósmicos por donde el sujeto lírico vivió y (re)vive su infancia evoca el mito del paraíso terrenal, el cual devela el deseo de existir en el mundo real, sagrado, para así «superar de manera natural la condición humana y descubrir la condición divina» (Eliade 1964: 322). Al respecto canta el sujeto lírico:

Todo la tierra. Oigo llover.

Las frutas dentro de ella corren

como días planetarios.

Un gusano dorado se detiene 
en la palma de mi desolación:

entre él y este día

hay llamas insalvables. (Albán 1992: 30)

Cada vez más, el sujeto lírico no solo se adentra en el espacio cósmico y las claridades, sino aun en el sueño, la figura del niño y la familia. Cada vez más se encamina hacia sus orígenes porque: «Éste es el secreto de los que siempre avanzan/ por un prado, soñándolo, como si no murieran» (Albán 1992: 94).

Por haber partido de su vigilia, haberse internado en la noche angustiante hasta el día del recuerdo, vía la mirada y la «memoria», el sujeto lírico experimenta un universo onírico, en el cual su presente y su infancia, lo telúrico y lo uránico, lo profano y lo sagrado, lo consciente y lo inconsciente se encuentran reunidos y equilibrados gracias al «árbol» flotante de su palabra poética sobre el «árbol/ lentísimo del tiempo»:

Tengo un árbol al fondo de mi voz.

Un árbol de rocíos poderosos.

Alta la copa y la raíz más alta,

y un pájaro forzado

a seguir en el aire para siempre. (Albán 1992: 112)

El «árbol» aparece como axis mundi: el eje del mundo psíquico, intuitivo, poético y religioso del sujeto lírico. Por eso, junto a este «árbol», la figura diáfana, inconsciente y eterna de «un dios de nueve años» (Albán 1992: 114) se levanta a recoger la memoria, «el día maravilloso» (1992: 112); busca «cosas recién nacidas/ en la nítida yedra del asombro» (1992: 114). El sujeto lírico lo llama «dios/ porque el oficio de los dioses/ es buscar y buscar entre el silencio/ días interminables» (1992: 114). Esta búsqueda es la suscitada por la intuición, el recuerdo, la mirada y la contemplación en el sujeto lírico. Por ende, en un acto especular, el uno se reconoce en el otro como consecuencia de la énstasis de la unitas indistinctionis:

Se yergue lentamente empapado de azules,

mira a lo lejos y me mira

y se asusta y sabemos que vivimos,

cada uno buscando el árbol

lentísimo del tiempo

la luz del otro que hacia el otro nace.

Este es un rito diario

que en mi sombra está vivo

como un esplendor:

el niño que en la niebla

busca el rostro del día,

y yo con el abismo

de sus ojos en mí. (Albán 1992: 112-114) 
Este «dios», en definitiva, es la «sombra» y el «esplendor»: la reunión de lo inconsciente y lo consciente. Él es la «niebla» y el «abismo»: lo sublime, el todo y la nada paradójicos del misterio sagrado, las fuerzas incognoscibles y primigenias de lo real. Él, por consiguiente, materializa el arquetipo del niño (Jung 2002a): esa imagen que representa el aspecto preconsciente de la infancia del alma; el estado originario, inconsciente e instintivo, o bien intuitivo; la posibilidad y el futuro en potencia, ya que surge como tertium entre lo inconsciente y la consciencia en medio de una situación de desarrollo, como figura salvífica, un hacedor-de-la-totalidad, expresión del ser inicial antes del sujeto -dígase profano- y el ser final después de este -llámeselo pleno místicamente-.

Este encuentro con el «niño» solo es posible en el universo onírico y trasciende a la consciencia del sujeto lírico gracias a la mediación del lenguaje. Por eso, la performatividad de la enunciación poética abre un espacio donde la existencia y el sueño, el presente y el recuerdo, lo nocturno y lo diurno se encuentran coimplicados y dependientes para permitir la totalidad psíquica del sujeto lírico:

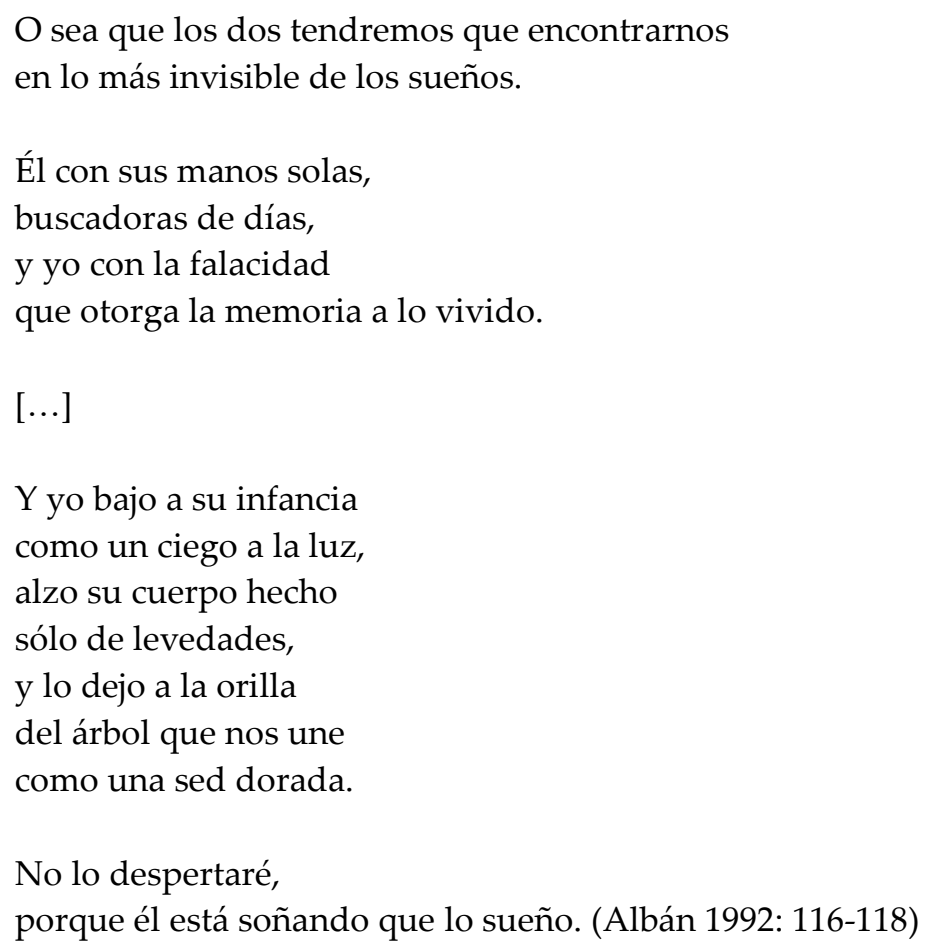

No lo despertaré, porque él está soñando que lo sueño. (Albán 1992: 116-118)

Hasta aquí una primera forma de acercarse al misterio de lo sagrado a través de la figura del niño. Sin embargo, otras maneras para el sujeto lírico serían precisamente sus relaciones con su «padre», «madre» y «hermana», figuras que indudablemente también son significativas para su infancia y su constitución psicológica, psíquica, poética y religiosa.

Primeramente canta: «Que el padre es una lámpara/ donde arde su memoria,/ y la madre una casa/ intensa como el día, abierta en el adiós» (Albán 
1992: 36-38). Ambos, «los ojos del padre/ y de la madre amándose,/ interminablemente,/ como un susurro mágico» (1992: 74), edifican el hogar, la morada que, por un lado, representa metonímicamente el cosmos; y, por otro, estimula existencial y místicamente el amor, la intuición y la mirada-recuerdo del ser para percibir y vivir la «verdad» trascendental. Obsérvese que el hogar aparece como símbolo de la intimidad. Estos se relacionan con los continentes y los contenidos, las imágenes de la interioridad y el reposo, debido al gesto del acurrucamiento y el reflejo digestivo (Durand 1982). Debido a esta morada hogareña, curioso, deseoso y en complicidad con su hermana, el sujeto lírico se acerca al recinto donde se encuentran sus padres y

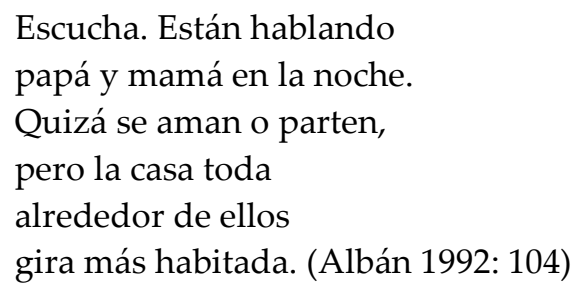

En esta imagen de totalidad doméstica-cósmica, su «papá» vendría a materializar el arquetipo del padre, el cual guía al ser y lo protege del mundo exterior, en compensación con la protección materna del mundo interior (Jung 1984). De ahí las referencias luminosas al evocar a su «papá», siempre al lado de «mamá» y en diálogo con ella.

La «madre», por otro lado, simboliza para el sujeto lírico la tranquilidad, la protección, el amor y la luz, inclusive aún después de fallecida. Su presencia es eterna, trascendente y misteriosa, de modo que su claridad indica la vía de la experiencia mística y aun de la producción poética, en medio de una cotidianidad donde todas las empresas sin distinción son sagradas, pues la sacralidad instrumental contribuye al establecimiento de una estructura mística (Ocáriz 2000). De ahí que el aplanchado de su «madre» no se diferencie de la escritura del sujeto lírico, pues ambas acciones, iguales en amor, configuran una realidad sagrada e instrumental de corredención (Rodríguez 1983). En relación con este párrafo, canta el sujeto lírico:

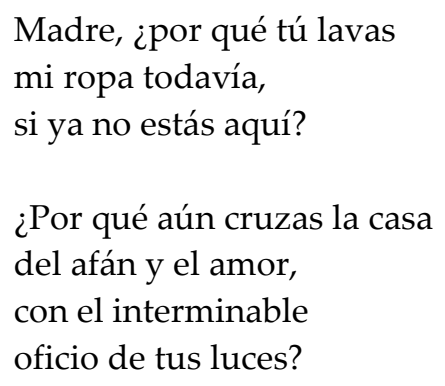

Has dejado ventanas tan abiertas en todo, que nunca será noche 
en mi sola palabra.

$[\ldots]$

Tú llegabas despacio

a la aurora o la mesa,

como un rayo que toca

las cosas sin olvido.

Madre, ahora mismo, aquí,

tan lejana y tan malva,

cuidas que mi poema

quede puro de sombra

como tu ropa clara.

Porque no hay diferencias

entre planchar camisas

o ganar las palabras.

Que todas las tareas

del amor son idénticas

a una luz en las manos.

$[\ldots]$

Que sólo he caminado

de un río a otro del canto.

Que sigo caminando

por el día inagotable

de tu blanca mirada. (Albán 1992: 106-110)

Claramente, esta figura materna materializa los rasgos positivos del arquetipo de la madre:

«lo materno», la autoridad mágica de lo femenino, la sabiduría y la altura espiritual que está más allá del entendimiento; lo bondadoso, protector, sustentador, dispensador de crecimiento, fertilidad y alimento; los sitios de la transformación mágica, del renacimiento; el impulso o instinto benéficos; lo secreto, lo oculto, lo sombrío, el abismo (Jung 1984: 75).

Arquetípicamente, su «madre» le posibilita al sujeto lírico el (re)nacimiento, el crecimiento y la transformación de su naturaleza profana hacia su naturaleza sagrada; de su pertenencia al tiempo histórico hacia su pertenencia al tiempo cíclico, onírico, místico.

Por su parte, el sujeto lírico evoca a su «hermana» como compañera de juego y vida:

Tú perteneces sólo

a la humedad más blanca,

la que impuso la luna

en todo lo mirado, 
apasionada de ámbar.

$[\ldots]$

Tú jugabas entonces

con no sé qué delicia

de muñeca y paisaje.

Sólo el aire podía

seguirte a lo soñado,

de tan leves que eran

las profecías del alba. (Albán 1992: 102)

Debido a su experiencia mística, el sujeto lírico siente la necesidad de proteger a su «hermana» del mundo profano -representado en los versos anteriores por el frío y la luna, símbolos teriomorfo y nictomorfo respectivamente- y guiarla con sus «azules» enseñanzas, hacerla cruzar igualmente hacia la claridad, hacia la «lluvia» que limpia la percepción y consciencia racional, purifica y fecunda las facultades intuitiva y contemplativa:

Hermana. Que hace frío.

Ponte el chaleco azul

y cruza por la lluvia

como entrando a los ojos

del cielo en movimiento. (Albán 1992: 102)

Obsérvese que la «lluvia» aparece en este contexto como un símbolo diairético. Estos se refieren al héroe, la virilidad, las armas, la belicosidad y la purificación (Durand 1982).

La «hermana» materializaría el arquetipo del anima: el complemento femenino del varón (Jung 1984). Por eso, la amorosa y filial reciprocidad existente entre ella y el sujeto lírico dentro del ámbito doméstico y didácticomístico.

Con base en lo anterior, se observa cómo las figuras del «niño», el «padre», la «madre»y la «hermana» articulan, para el sujeto lírico, una cuaternidad. Según Jung, una cuaternidad corresponde a «un múltiplo de cuatro en forma de cruz o de estrella o de un cuadrado, octógono, etc.», que aparece dentro de un mándala y representa «la unión de los cuatro elementos que tienden a disociarse» (2002b: 371). Con base en este concepto, obsérvese que las relaciones entre el sujeto lírico y su «padre», «madre» y «hermana» construyen una imagen cósmica, dinámica y correspondiente de todos los elementos arquetípicos y simbólicos de la realidad imaginaria, ontológica, existencial y mística del sujeto lírico, en medio del cronotopo de su experiencia religiosa. De ahí que el ambiente onírico-místico a lo largo de este poemario sea noche-día, luz lunar-luz solar, prado-casa, macrocosmos-microcosmos, pasado-presente, lo consciente-lo inconsciente, lo terrestre-lo celestial, el yo-el otro, el uno-el Uno; en fin, este ambiente sea una auténtica coincidentia oppositorum, una totalidad: 
una suma de claridades. La cuaternidad formada por las figuras del «niño», el «padre», la «madre» y la «hermana» demuestra, en efecto, la unidad del sujeto lírico y su situación evolutiva: su experiencia religiosa.

\section{Conclusiones}

La experiencia mística en Suma de claridades se desarrolla en torno a la mirada, el recuerdo, la visión onírica de la infancia, los paisajes de la niñez, la claridad, las figuras del «niño», el «padre», la «madre» y la «hermana».

Antes que un tono nostálgico y disfórico, se emplea un lenguaje eufórico, en que redundan símbolos espectaculares, diairéticos y ascensionales, de la inversión y cíclicos, con el fin de representar y construir un mundo luminoso, puro y pleno, un ámbito paradisíaco de reposo y protección, en el cual y a través del cual el sujeto lírico, en cuanto homo religiosus o místico, vive el misterio de lo sagrado y su reintegración con lo trascendente.

En la plenitud cósmica de los «prados» y «abril», el sujeto lírico supera la noche angustiante y el tiempo histórico de la realidad profana. Estos son representados por símbolos nictomorfos, catamorfos y teriomorfos. Su viaje se intensifica cada vez más como la «luz», hasta adentrarse en las claridades que trascienden desde lo inconsciente y lo real, para llevarlo hacia una unio mystica, una vivencia unificadora: «de la infancia/ totalmente empapado/ de madre y manzanas» (Albán 1992: 72).

La poesía para Laureano Albán comprende una labor y búsqueda de lo trascendental en lo cotidiano y desde ello. Su objetivo siempre ha sido cantar la revelación de realidades metafísicas y ontológicas; aquellas experiencias en su mayoría comunes que el ser se ha acostumbrado a percibir cada vez menos, debido a los procesos de una visión materialista o fenomenológica de las realidades (pos)modernas. Por eso, para este poeta costarricense: «Decir poesía mística es un pleonasmo, porque toda verdadera poesía, si lo es, a su manera, siempre será mística» (palabras tomadas de un correo electrónico enviado por Albán, el 13 de octubre de 2014, al poeta madrileño Domingo Díaz y al investigador). El sujeto lírico, o bien místico, de Suma de claridades, confirma este aserto, ya que muestra cómo la infancia cotidiana «es el secreto/ de lo maravillado,/ de lo eterno y lo rápido,/ del pacto inagotable/ de las cosas del mundo/ con los mundos del sueño» (Albán 1992: 96-98).

BIBLIOGRAFÍA

AlBÁN, L. (1992), Suma de claridades, Sevilla, Fundación Fernando Rielo. 
BERTíN, G. (1967), Diccionario literario, Barcelona, Montaner y Simón.

BULGARELLI, P. (7, OCTUBRE, 1995), «De la razón al asombro», La Nación, 1B.

CAMPOS, R. (2015), Antología poética de Laureano Albán, Valladolid, Agilice Digital.

CAMPOS, R. (2016), «Innovaciones simbólicas en Infinita memoria de América, de Laureano Albán», Castilla, 7, 144-168.

CHARPENTIER, J. (24, abril, 1994), «Los nocturnos de Julieta», La Nación, 2-3D.

Chevalier, J. y GHeerbrant, A. (1988), Diccionario de los símbolos, Barcelona, Herder.

DOUCET, M. (2010), «Prólogo», en Enciclopedia de maravillas, Albán, L., vol. 4, Pittsburg, International Poetry Forum, 8-10.

DURAND, G. (1982), Las estructuras antropológicas de lo imaginario, Madrid, Taurus.

ELIADE, M. (1964), Tratado de historia de las religiones, vol. 1, Madrid, Cristiandad.

CAMPOS, R. (1974), Tratado de historia de las religiones, vol. 2, Madrid, Cristiandad.

FORNOFF, F. y MCCLINTOCK, S. (1995), «Después del boom, una explosión de poesía», en Enciclopedia de maravillas, Albán, L., vol. 1, Pittsburg, International Poetry Forum, 17-37.

García Gual, C. (2011), Mitos, viajes y héroes, México, Fondo de Cultura Económica.

GARCíA-BARÓ, M. (2004), «Más yo que yo mismo. Un ensayo en los fundamentos de la filosofía de la mística», en La experiencia mística. Estudio interdisciplinario, Velasco, J. (ed.), Madrid, Trotta, 285-309.

JUNG, C. (1984), Arquetipos e inconsciente colectivo, Barcelona, Paidós.

JUNG, C. (2002a), «Acerca de la psicología del arquetipo del niño», en Obra completa. Los arquetipos y lo inconsciente colectivo, Helvetia, Fundación suiza para la cultura y Erbengemeinschaft C.G. Jung (eds.), Madrid, Trotta, 139-168.

JUNG, C. (2002b), «Mándalas», en Obra completa. Los arquetipos y lo inconsciente colectivo, Helvetia, Fundación suiza para la cultura y Erbengemeinschaft C.G. Jung (eds.), Madrid, Trotta, 371-374.

MCGINN, B. (1989), «Love, Knowledge and Unio Mystica in the Western Christian Tradition», en Mystical Union and Monotheistic Faith. An Ecumenical Dialogue, Idel, M. y McGinn, B. (eds.), Nueva York / Londres, Macmillan, 59-86.

McGinN, B. (1992), The Presence of God: A History of Western Christian Mysticism, Londres, SCM Press.

OCÁRIZ, F. (2000), Naturaleza, gracia y gloria, Pamplona, Eunsa.

OsPINA, H. (2003), La poesía mística en Costa Rica. ¿Un género marginal? [Consulta: 16 marzo 2015]. Disponible en: <http://arvo.net/seccion-promesa/la-poesia-misticaen-costa-ric/gmx -niv164-con10330.htm>

Oтто, R. (1925), Lo santo. Lo racional y lo irracional en la idea de Dios, Madrid, Revista de Occidente.

PASCUAL, F. (2004), «Reseña del seminario «El fenómeno místico. Estudio Interdisciplinario»», en La experiencia mística. Estudio interdisciplinario, Velasco, J. (ed.), Madrid, Trotta, 349-356.

PAZ, O. (1971), Las peras del olmo, Barcelona, Seix Barral.

PAZ, O. (1998), El arco y la lira, México, Fondo de Cultura Económica.

Pieragnolo, T. (2011), «Prefazione», en Poesie imperdonabili, Albán, L., Italia, Passigli, 5-12.

RODRÍGUEZ, P. (1983), «Reflexión teológica sobre el trabajo», Scripta Theologica, 15, 198.

RoY, L. (2001), Le sentiment de transcendence, experience de Dieu?, París, Cerf. 
SANCHO, L. (2009), La voz otra en Sor Juana Inés de la Cruz, San José, Editorial Universidad de Costa Rica.

Schimmel, A. (1996), Wie universal ist die Mystik? Die Seelenreise in den grossen Religionen der Welt, Freiburg, Herder.

VELASCO, J. (2004), «El fenómeno místico en la historia y en la actualidad», en La experiencia mística. Estudio interdisciplinario, Velasco, J. (ed.), Madrid, Trotta, 15-49. 